\title{
Thermoregulatory Nonshivering Thermogenesis in Men, with Special Reference to Lipid Metabolism
}

\author{
Katsuhiko DoI, Tomie OHno,* Masashi Kurahashi, \\ and Akihiro Kuroshima \\ Department of Physiology, Asahikawa Medical College, Nishikagura, \\ Asahikawa, 078-11 Japan, \\ *Division of Nutrition Physiology, Hokkaido Educational College, \\ Hokumon-cho 9, Asahikawa, 070 Japan
}

\begin{abstract}
The existence of thermoregulatory nonshivering thermogenesis, with special reference to lipid metabolism, was investigated in men.

Acute cold exposure $\left(10^{\circ} \mathrm{C}, 60 \mathrm{~min}\right)$ produced a marked increase in heat production, with concomitant elevation of plasma free fatty acid (FFA) level, modest increase of ketone body concentration and lowered respiratory quotient (R.Q.). The correlation of heat production to plasma FFA levels was significantly positive; that is, subjects with higher heat production showed higher plasma FFA levels. Moreover, correlation of either heat production or plasma FFA levels to R.Q. was significantly negative, respectively. On the other hand, exposure to cold after an administration of nicotinic acid, which has a suppressive effect on FFA mobilization from adipose tissue, resulted in less cold-elevated heat production, a significant fall of plasma FFA and ketone body concentrations, and no change in R.Q. Although no visible or only slight shivering was observed in control cold exposure study, greater shivering occurred in the nicotinic acid cold exposure study.

These results appear to indicate that nonshivering thermogenesis as a source of heat production achieved by enhanced utilization of lipids is also present in men.
\end{abstract}

Enhanced nonshivering thermogenesis has been indicated as a characteristic index of cold adaptation in rats (SELLERS et al., 1954; HART et al., 1956). The decrease in shivering has been noted in cold-adapted men (IRVING, 1960). The evidence of regulatory nonshivering thermogenesis in men was first presented by DAVIs (1961). Men could be artificially (DAVIS, 1961) and seasonally (DAvis and JoHNSTON, 1961) acclimated to cold by means of nonshivering thermogenesis. HuRley et al. (1964) and GIRLING (1964) also confirmed the presence of nonshivering thermogenesis in men acclimated to cold climate. As to the mechanism

Received for publication November 24, 1978

土居勝彦, 大野都美恵, 倉橋昌司, 黒島晨沉 
involved, Joy (1963) found that norepinephrine may be the primary mediator of nonshivering thermogenesis occurring with cold acclimation in men. IтоH (1974) and his coworkers suggested that the Ainu, aboriginal inhabitants in Hokkaido, the northernmost island of Japan, is equipped with adaptive mechanism characterized by norepinephrine-sensitive thermogenesis. These previous results apparently indicate that cold acclimation in men is also closely associated with enhanced nonshivering thermogenesis, which is mainly regulated by norepinephrine. On the contrary, GLICKMAN et al. (1967) have shown that the increase in heat production in the cold was directly proportional and almost entirely attributable to the activity of muscle in seasonally cold-acclimated men. KANG et al. (1970) also suggested that the development of nonshivering thermogenesis is not the main feature of cold acclimation in men, at least in Korean women divers. However, men living in Hokkaido were considered to be well adapted to cold, especially in winter. During the winter they exhibit higher levels of basal metabolism (OHNO and KuROSHIMA, 1973), plasma free fatty acids (FFA) and urinary excretion of nitrogen (Kuroshima et al., 1973). Men born in Hokkaido also showed the greater cold adaptability than those born in Honshu the main island in the pressor response and the finger temperature response to local cooling (Iтон, 1974), which have been used as one of the methods for the assessment of cold adaptability.

Therefore, it seems to be interesting to clarify whether or not any specific signs of cold acclimatization are observed in the subjects who are adapted to winter cold in Hokkaido, and whether nonshivering thermogenesis can be found in them. The present experiments were designed to verify the presence of nonshivering thermogenesis and furthermore to elucidate the mechanism of nonshivering thermogenesis in men.

\section{SUBJECTS AND METHODS}

Experiments were conducted to ten male medical students, aged 18-26 years, in Asahikawa in Hokkaido, Japan. Their physical characteristics are shown in Table 1. The thickness of double folds of skin and subcutaneous fat at 10 sites recommended by ALLEN et al. (1956) were measured with Harpenden skinfold caliper (British Indication Co., Ltd.). The experiments were conducted during the winter, January and February. Meteorological data in Asahikawa are tabulated

Table 1. The physical characteristics of the subjects.

\begin{tabular}{|c|c|c|c|c|c|}
\hline Subjects & Age & Ht. (cm) & Wt. (kg) & $\begin{array}{c}\text { Surface } \\
\text { area }\left(\mathrm{m}^{2}\right)\end{array}$ & $\begin{array}{c}\text { Skinfold } \\
\text { thickness(mm) }\end{array}$ \\
\hline Male students (10) & $22 \pm 1.0$ & $170 \pm 1.8$ & $63 \pm 2.2$ & $1.72 \pm 0.037$ & $9.9 \pm 1.52$ \\
\hline
\end{tabular}


Table 2. Mean outdoor temperature $\left({ }^{\circ} \mathrm{C}\right)$.

\begin{tabular}{ccccccccccccc}
\hline Place & Jan. & Feb. & Mar. & Apr. & May & Jun. & Jul. & Aug. & Sept. & Oct. & Nov. Dec. \\
\hline $\begin{array}{l}\text { Asahikawa } \\
(1941-70)\end{array}$ & -8.5 & -7.7 & -3.0 & 4.5 & 11.4 & 16.1 & 20.4 & 20.9 & 15.3 & 8.5 & 1.3 & -4.9 \\
\hline
\end{tabular}

in Table 2. The subjects had previously wintered in the area more than three times. Histories of the subjects did not reveal any remarkable thermal backgrounds, serious diseases nor any suggestion that the subjects lived differently from other individuals in the college. The activities of subjects were of a sedentary nature and none participated in activities that would increase physical fitness before and during the period of study.

Two series of tests were performed on the same subjects in each experiment. In the first (control study) experiment, the subjects wearing only $\mathrm{T}$ shirts and shorts were exposed to a standard cold exposure (temperature, $10^{\circ} \mathrm{C}$; relative humidity, $60-70 \%$; wind velocity, less than $0.5 \mathrm{~m} / \mathrm{sec}$ ) in a supine position on the bed. The second (nicotinic acid study) experiment was carried out 3-4 days later, the subjects were submitted to the same cold exposure as in the control study after an administration of an oral dose of $200 \mathrm{mg}$ nicotinic acid just before the exposure to cold. The subjects reported to the laboratory at 8:00 a.m. in a postabsorptive state that lasted for about $12 \mathrm{hr}$ and were made to rest under a blanket on a bed for $1 \mathrm{hr}$ before the experiment. After $1 \mathrm{hr}$ stabilization, the initial measurements of heat production, rectal and skin temperatures, pulse rate, and blood pressure were performed. The oxygen consumption was determined before and during cold exposure. On each occasion, the expired gas over a period of $10 \mathrm{~min}$ was collected in Douglas bag with a face mask, measured with a dry gas meter and an aliquot of sample was analyzed for $\mathrm{O}_{2}$ and $\mathrm{CO}_{2}$ with Scholander micrometer gas analyzer. Pulse rate was determined every $5 \mathrm{~min}$ before and during cold exposure by counting the radial pulse for $30 \mathrm{sec}$. Blood pressure was measured with a mercury sphygmomanometer every $5 \mathrm{~min}$ before and during exposure to cold. Skin temperatures were continuously and simultaneously recorded by a thermistor thermometer (TER-36, Takara Kogyo, Co., Ltd., Tokyo) at five different locations (forehead, chest, abdomen, thigh and calf) on the body. Rectal temperature was obtained by a thermistor thermometer probe inserted in the anus, and extending $10 \mathrm{~cm}$ beyond, and secured by tape. An average skin temperature was calculated by multiplying the temperature at five locations mentioned above as proposed by MorRISON (1965). Mean body temperature was calculated as the sum of 0.67 times the rectal temperature and 0.33 times the average skin temperature (BUSKIRK et al., 1963). Body heat content was calculated as the product of mean body temperature times the specific heat of the tissue $\left(0.83 \mathrm{kcal} / \mathrm{g} \cdot{ }^{\circ} \mathrm{C}\right)$ times the body weight in $\mathrm{kg}$ (Burton and EDHolm, 1955). Heat loss in the cold was expressed as the difference between the initial heat content and the heat content after cold exposure. A measurement of tissue body insulation $\left(I_{b}\right)$ was derived from the equation 
(CARLSON, 1954): $I_{\mathrm{b}}=\left(T_{\mathrm{r}}-\bar{T}_{\mathrm{s}}\right) / 0.76 M$, where 0.76 , correction constant for evaporate heat loss (assumed to be $24 \%$ ); $T_{\mathrm{r}}$, rectal temperature; $\bar{T}_{\mathrm{s}}$, average skin temperature; and $M$, metabolism.

Immediately after initial measurements, the subjects were transferred into the cold room. In the cold, the subjects lay fully extended with legs spread apart and arms away from the body. The same measurements as in the controls were made periodically during cold exposure.

Shivering was estimated by the inspection every 1 min throughout cold exposure by the same observer in every experiment and recorded according to a 4-point scale (0-3), corresponding to none, mild, severe and violent shivering. Onset of shivering was observed by the observer and evaluated by the subjects.

Eight $\mathrm{ml}$ of blood sample was obtained from the antecubital vein simultaneously with the collection of the expired gas. Plasma concentration of FFA was determined by the method of ITAYA and UI (1965), plasma glucose by the anthrone reagent method (RoE, 1955) and plasma $\beta$-hydroxybutyrate by the enzymatic method of GIBBARD and WATKINS (1968). Plasma total protein content was determined with a protein refractometer (Hitachi, Ltd., Tokyo).

Results were expressed as means \pm standard errors. The statistical significance of the results was tested by Student $t$-test. Linear regressions were determined by the method of least squares.

\section{RESULTS}

Changes in heat production after cold exposure

As shown in Table 3, exposure to cold produced a significant increase in the heat production in the control study. The heat production increased from $38.9 \pm 2.44 \mathrm{kcal} / \mathrm{m}^{2} \cdot \mathrm{hr}$ to $51.9 \pm 2.24(+33.4 \%, p<0.001) 30 \mathrm{~min}$ and to $62.6 \pm 4.10$ $(+60.9 \%, p<0.001) 60$ min after cold exposure. An administration of nicotinic acid brought about a significant reduction in the elevation of heat production $60 \mathrm{~min}$ after exposure to cold.

Table 3. The changes in the heat production and R.Q. in response to cold.

\begin{tabular}{|c|c|c|c|c|c|c|c|}
\hline $\begin{array}{l}\text { Time after cold } \\
\text { exposure (min) }\end{array}$ & 0 & 15 & $p$ vs. 0 & 30 & $p$ vs. 0 & 60 & $p$ vs. 0 \\
\hline & \multicolumn{7}{|c|}{ Heat production $\left(\mathrm{kcal} / \mathrm{m}^{2} \cdot \mathrm{hr}\right)$} \\
\hline \multicolumn{8}{|l|}{ Male students } \\
\hline Control study (10) & $38.9 \pm 2.44$ & $46.2 \pm 3.19$ & N.S. & $51.9 \pm 2.24$ & $<0.001$ & $62.6 \pm 4.10$ & $<0.001$ \\
\hline NA-study (10) & $40.0 \pm 2.39$ & $45.6 \pm 3.88$ & N.S. & $56.1 \pm 7.16$ & N.S. & $50.2 \pm 3.21$ & $<0.05$ \\
\hline Control vs. NA & N.S. & N.S. & & N.S. & & $<0.05$ & \\
\hline \multicolumn{8}{|c|}{ R.Q. } \\
\hline Control study(10) & $0.84 \pm 0.011$ & $0.82 \pm 0.018$ & N.S. & $0.80 \pm 0.012$ & $<0.001$ & $0.79 \pm 0.013$ & $<0.001$ \\
\hline NA-study (10) & $0.82 \pm 0.017$ & $0.84 \pm 0.014$ & N.S. & $0.85 \pm 0.011$ & N.S. & $0.84 \pm 0.018$ & N.S. \\
\hline Control vs. NA & N.S. & N.S. & & $<0.01$ & & $<0.05$ & \\
\hline
\end{tabular}

Each value represents the mean \pm standard error. Number in the parenthesis indicates the number of subjects. NA: nicotinic acid. N.S.: not significant. 
The values of R.Q. were calculated in order to assess the preferential substrates utilized during cold exposure (Table 3 ). The initial value of $0.84 \pm 0.001$ declined to $0.80 \pm 0.012(p<0.001) 30 \mathrm{~min}$ and to $0.79 \pm 0.013(p<0.001) 60 \mathrm{~min}$ after cold exposure in the control study. On the other hand, in the nicotinic acid study the values of respiratory quotient (R.Q.) remained at the initial level throughout cold exposure.

\section{Shivering and its onset time}

Figure 1 shows that there was only slight shivering in the control study. The average shivering score was $0.3 \pm 0.03$ units $(p<0.01) 30 \mathrm{~min}$ and $1.0 \pm 0.11$ $(p<0.01) 60 \mathrm{~min}$ after cold exposure, while, in the nicotinic acid study, the same cold exposure caused a marked increase in shivering. Shivering elevated to the extent of $2.5 \pm 0.27$ units $(p<0.001) 30 \mathrm{~min}$ and to $3.0 \pm 0.41(p<0.001) 60 \mathrm{~min}$ following cold exposure. Significant greater increases have been observed in the extent of shivering $30 \mathrm{~min}(p<0.001)$ and $60 \mathrm{~min}(p<0.001)$ after cold exposure in the nicotinic acid study as compared with the corresponding values in the control study. Mean onset time of shivering after cold exposure was $18 \pm 2.1 \mathrm{~min}$ in the control study and $4 \pm 0.34$ in the nicotinic acid study. These results indicate that shivering occurred more rapidly $(p<0.001)$ in the nicotinic acid study than in the control study.

Changes in blood constituents after cold exposure

The effect of cold exposure on blood substrates is summarized in Table 4. The plasma levels of FFA measured simultaneously with the heat production

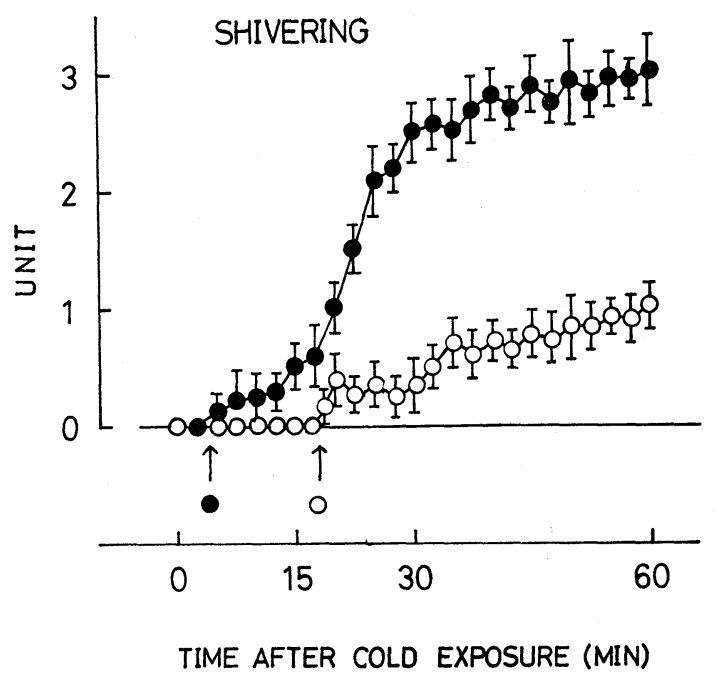

Fig. 1. Changes in the shivering after cold exposure. $\bigcirc$, cold exposure $\left(10^{\circ} \mathrm{C}\right)$; $\bullet$, cold exposure after an administration of nicotinic acid. Arrow indicates the onset of shivering. Vertical bar denotes standard error. 


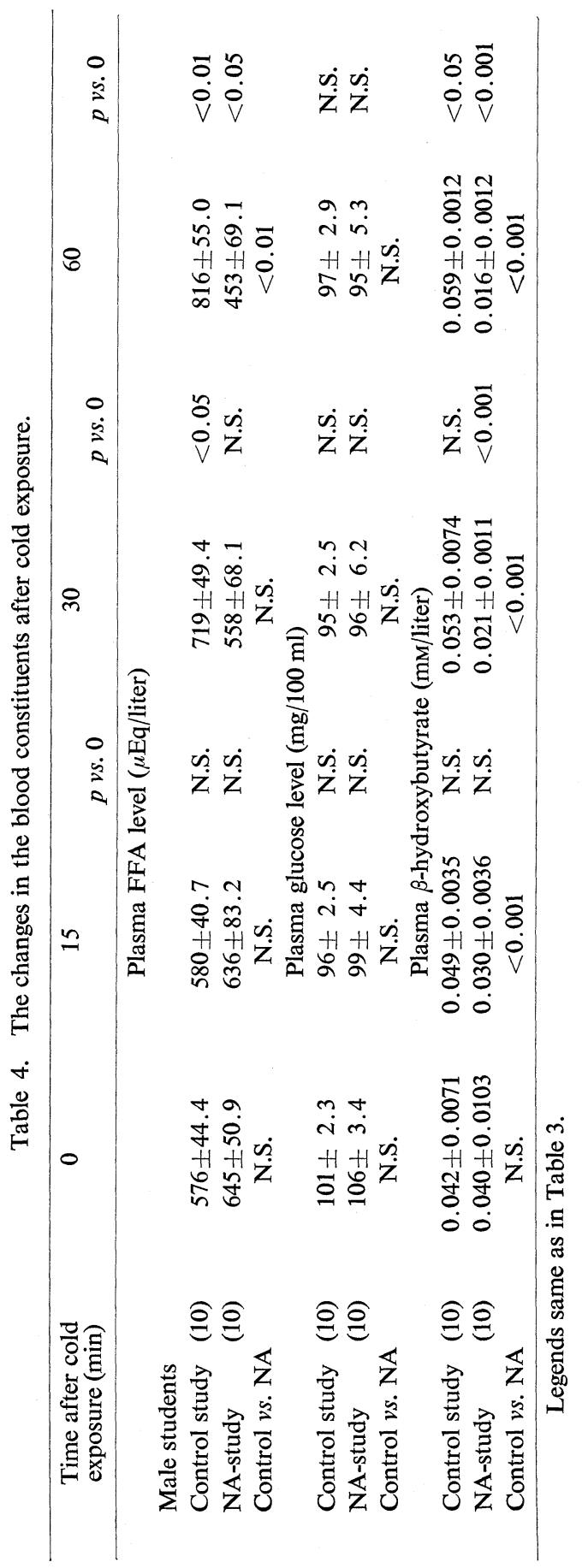




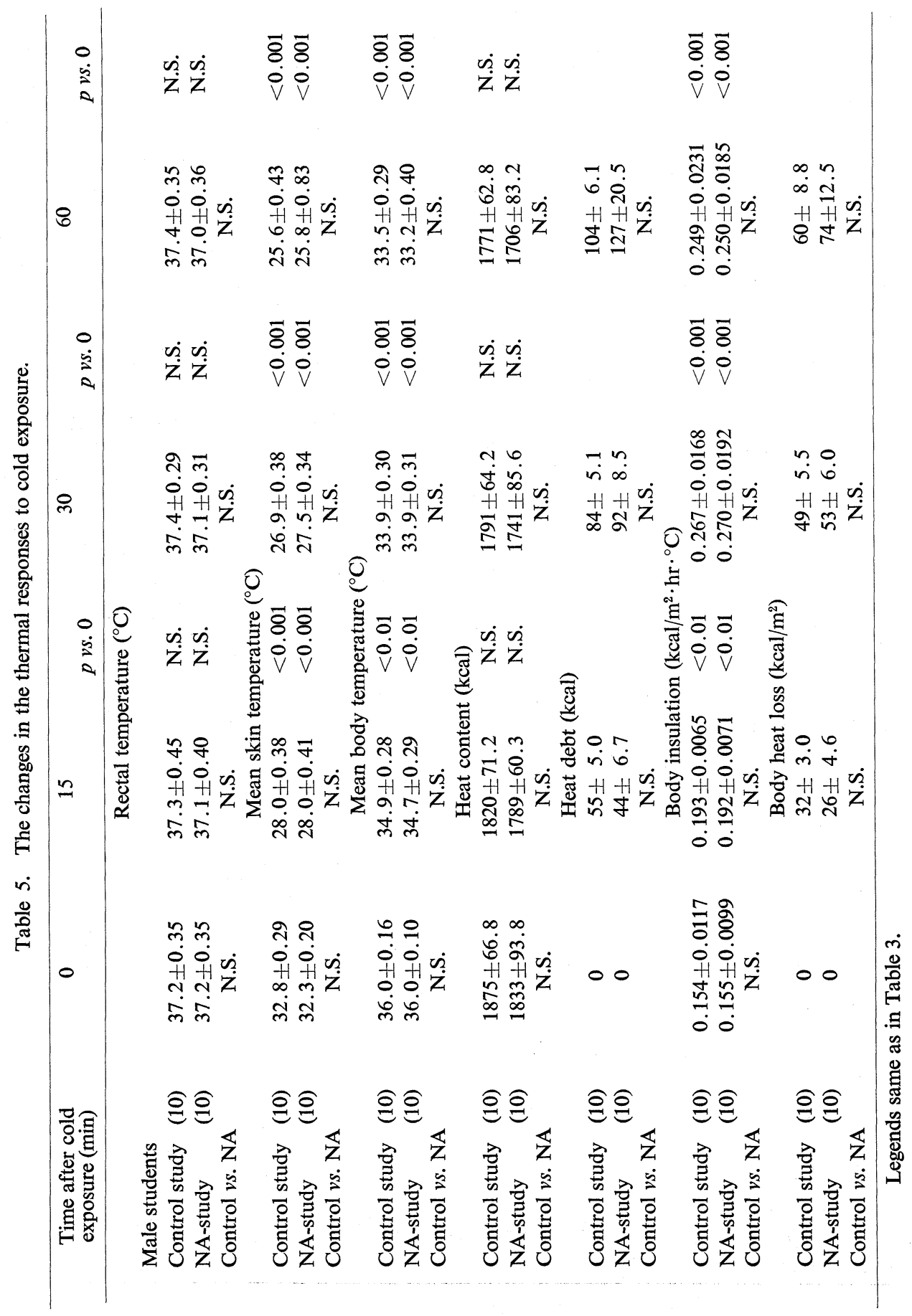

Vol. 29, No. 4, 1979 
elevated significantly from $576 \pm 44.4 \mu \mathrm{Eq} /$ liter to $719 \pm 49.4(24.8 \%, p<0.05)$ $30 \mathrm{~min}$ and to $816 \pm 55.0(41.7 \%, p<0.01) 60 \mathrm{~min}$ after cold exposure in the control study. After an administration of nicotinic acid, the increment of plasma FFA due to cold was completely abolished. On the contrary, a pronounced fall from $645 \pm 50.9 \mu \mathrm{Eq} /$ liter to $453 \pm 69.1(42.4 \%, p<0.05)$ was observed $60 \mathrm{~min}$ after cold exposure. Ketone bodies, measured as $\beta$-hydroxybutyrate, increased from 0.042 土 $0.0071 \mathrm{~mm} /$ liter to $0.059 \pm 0.0012(p<0.05) 60 \mathrm{~min}$ after cold exposure in the control study, while it decreased from $0.040 \pm 0.0013 \mathrm{~mm} /$ liter to $0.021 \pm 0.0011$ $(p<0.001) 30 \mathrm{~min}$ and to $0.016 \pm 0.0012(p<0.001) 60 \mathrm{~min}$ following cold exposure in the nicotinic acid study.

Variations of core and peripheral temperatures, heat content, heat debt, heat loss and body insulation in the cold

As shown in Table 5, small changes in the rectal temperature was observed during cold exposure, though it was not significantly different. Mean skin temperature fell sharply, up to $30 \mathrm{~min}$, after cold exposure and thereafter decreased at a relatively slow rate up to $60 \mathrm{~min}$. There was no significant difference in the rate of fall between the control and nicotinic acid studies. The pattern of fall in the mean body temperature was essentially the same as that observed in the mean skin temperature. There was a progressive and significant decline up to the end of cold exposure, but no significant difference in the extent of decrease between two studies. There was a small decline in the heat content, heat loss and a little change in the heat debt in both control and nicotinic acid studies, but their variations in response to cold were not significantly different between two studies. The marked elevation of the body insulation was observed during cold exposure, but there was no significant difference between two studies.

Table 6. The changes in pulse rate and blood pressure after cold exposure.

\begin{tabular}{|c|c|c|c|c|c|c|c|c|}
\hline \multicolumn{2}{|l|}{$\begin{array}{l}\text { Time after cold } \\
\text { exposure (min) }\end{array}$} & 0 & 15 & $p v s .0$ & 30 & $p$ vs. 0 & 60 & $p v s .0$ \\
\hline \multicolumn{9}{|c|}{ Pulse rate (counts/min) } \\
\hline $\begin{array}{l}\text { Male students } \\
\text { Control study } \\
\text { NA-study } \\
\text { Control vs. NA }\end{array}$ & $\begin{array}{l}(10) \\
(10)\end{array}$ & $\begin{array}{l}60 \pm 5.0 \\
59 \pm 3.0 \\
\text { N.S. }\end{array}$ & $\begin{array}{c}59 \pm 3.2 \\
59 \pm 2.8 \\
\text { N.S. }\end{array}$ & $\begin{array}{l}\text { N.S. } \\
\text { N.S. }\end{array}$ & $\begin{array}{l}57 \pm 5.2 \\
61 \pm 4.5 \\
\text { N.S. }\end{array}$ & $\begin{array}{l}\text { N.S. } \\
\text { N.S. }\end{array}$ & $\begin{array}{l}60 \pm 3.3 \\
62 \pm 4.0 \\
\text { N.S. }\end{array}$ & $\begin{array}{l}\text { N.S. } \\
\text { N.S. }\end{array}$ \\
\hline $\begin{array}{l}\text { Control study } \\
\text { NA-study } \\
\text { Control vs. NA }\end{array}$ & $\begin{array}{l}(10) \\
(10)\end{array}$ & $\begin{array}{c}112 \pm 3.8 \\
110 \pm 3.5 \\
\text { N.S. }\end{array}$ & $\begin{array}{c}\text { Bloo } \\
128 \pm 5.3 \\
131 \pm 6.0 \\
\text { N.S. }\end{array}$ & $\begin{array}{l}\text { d pressure } \\
<0.05 \\
<0.01\end{array}$ & $\begin{array}{c}\text { (systolic) } \\
127 \pm 4.7 \\
132 \pm 5.8 \\
\text { N.S. }\end{array}$ & $\begin{array}{l}(\mathrm{mmHg}) \\
<0.05 \\
<0.01\end{array}$ & $\begin{array}{c}130 \pm 7.1 \\
131 \pm 7.3 \\
\text { N.S. }\end{array}$ & $\begin{array}{l}<0.05 \\
<0.05\end{array}$ \\
\hline $\begin{array}{l}\text { Control study } \\
\text { NA-study } \\
\text { Control vs. NA }\end{array}$ & $\begin{array}{l}(10) \\
(10)\end{array}$ & $\begin{array}{l}76 \pm 2.0 \\
75 \pm 2.2 \\
\text { N.S. }\end{array}$ & $\begin{array}{l}\text { Bloo } \\
90 \pm 6.0 \\
94 \pm 5.2 \\
\text { N.S. }\end{array}$ & $\begin{array}{l}\text { d pressure } \\
<0.05 \\
<0.001\end{array}$ & $\begin{array}{c}\text { (diastolic) } \\
92 \pm 6.2 \\
95 \pm 6.0 \\
\text { N.S. }\end{array}$ & $\begin{array}{l}(\mathrm{mmHg}) \\
<0.05 \\
<0.001\end{array}$ & $\begin{array}{l}88 \pm 3.8 \\
92 \pm 4.5 \\
\text { N.S. }\end{array}$ & $\begin{array}{l}<0.05 \\
<0.001\end{array}$ \\
\hline
\end{tabular}

Legends same as in Table 3. 


\section{Changes in pulse rate and blood pressure after cold exposure}

As can be seen in Table 6, the pulse rate remained unchanged during cold exposure in two studies. Both systolic and diastolic blood pressures were similarly elevated during cold exposure in two studies (Table 6).

\section{DISCUSSION}

As can be seen in Table 3, acute cold exposure produced a marked elevation of heat production in the control study already $30 \mathrm{~min}$ after cold exposure, although there appeared only slight shivering during this early period of cold exposure. These findings suggest that there exists nonshivering thermogenesis in men. However, these results do not exclude the possibility that even when shivering is not evident, the elevated heat production might be attributable to the increase in muscular tension (SWIFT, 1932; BuRTON and EDHOLM, 1955). Therefore, even if there exists a certain amount of nonshivering thermogenesis involved in the elevated heat production, participation of muscle activity could not be denied. If it is possible to reduce or eliminate nonshivering thermogenesis, shivering must become greater to compensate for the reduced nonshivering thermogenesis. In this context, it is of interest to refer to our previous report (Dor et al., 1969) and the study by HAvel et al. (1964). Dor et al. (1969) showed that an administration of nicotinic acid produced a significant decrease of plasma FFA levels accompanied by a decrease in basal metabolism. Furthermore, according to HAVEL et al. (1964), the calorigenic effect of norepinephrine was partially inhibited by prior injection of nicotinic acid in quantities sufficient to prevent fat mobilizing action of norepinephrine. These results would appear to indicate that nonshivering thermogenesis is mediated by an increased mobilization of FFA due to norepinephrine. As would be expected, an administration of nicotinic acid prior to cold exposure resulted in the significant reduction of plasma FFA level, less elevation of heat production and a greater increase in shivering (Tables 3, 4 and Fig. 1). It was also demonstrated that the occurrence of generalized shivering was observed earlier in the nicotinic acid study than in the control study. These results may be explained as follows: since nonshivering thermogenesis was reduced due to the decreased supply of FFA as a fuel substrate, the intensity of shivering became greater to compensate for the reduced nonshivering thermogenesis. In any case, the present study has demonstrated that nonshivering thermogenesis as a source of heat production develops in men in the cold and it is achieved by enhanced utilization of lipids as conjectured by the fact that nicotinic acid inhibits nonshivering thermogenesis as well as lipid mobilization. In fact, men living in Hokkaido were reported to exhibit higher levels of basal metabolism (OHNO and Kuroshima, 1973), plasma FFA and urinary excretion of nitrogen during the winter (Kuroshima et al., 1973). Thus, nonshivering thermogenesis is considered to develop in men in the cold due to the modified metabolism of energy-yielding 
substrates.

It is presently believed that the lipids are the most important fuel in the cold in men as well as animals (IтоH et al., 1969; MASORo, 1966). An immediate and marked increase occurs in the plasma FFA level as an invariable response to low environmental temperature. The elevation of plasma FFA levels indicate the occurrence of an augumented fat mobilization during cold exposure. This was also the case in the present study. In fact, the marked increase of plasma FFA levels was observed in the control study during cold exposure, as seen in Table 4. The increase in total plasma protein and hematocrit, and the decrease in plasma volume were well-known effects of cold exposure. The study by WILsON et al. (1969) showed that the increase in plasma FFA levels was not significant when FFA levels were corrected for cold hemoconcentration. In the present study, however, this hemoconcentration (5.4 to $8.8 \%$ in terms of hematocrit and 5.0 to $8.1 \%$ in terms of plasma total protein) could not account for the elevation of plasma concentration of FFA (24.8 to $41.7 \%$ ) in response to cold exposure. When the values of heat production were plotted against the plasma FFA levels, a significant, positive correlation was obtained $(p<0.01)$, as illustrated in Fig. 2 . These findings support the concept that the increase in heat production due to cold exposure is possibly associated with the elevation of the mobilization and oxidation of FFA. Moreover, the values of R.Q. declined significantly in accordance with the elevated heat production in the control study, while no change in R.Q. was observed in the nicotinic acid study. As shown in Figs. 3 and 4, there was a significant inverse correlation either between R.Q. and the plasma FFA levels $(p<0.005)$ or between R.Q. and heat production in the control study $(p<0.001)$. Consequently, it is very likely that a marked increase in heat production in men in the cold is as-

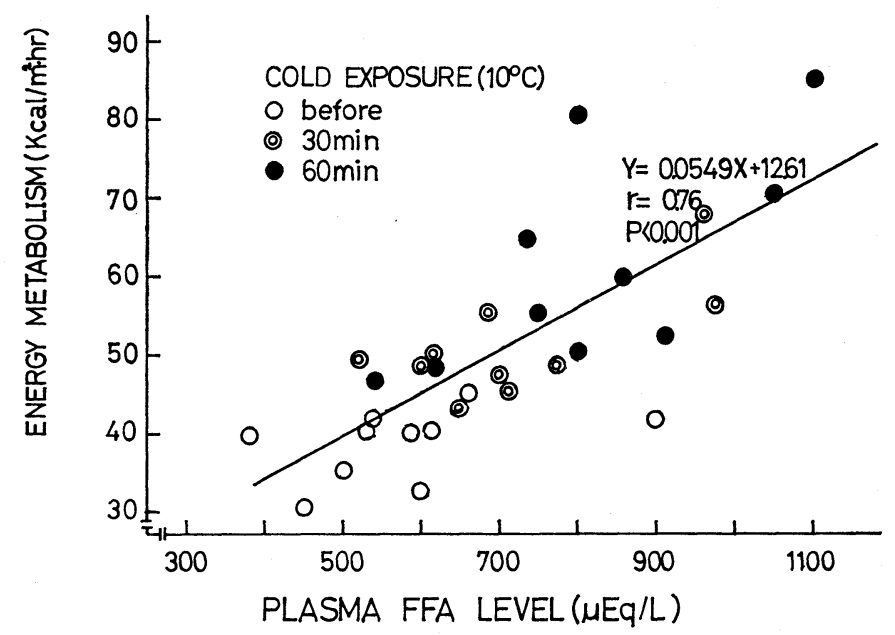

Fig. 2. Correlation between the heat production and plasma FFA levels. 


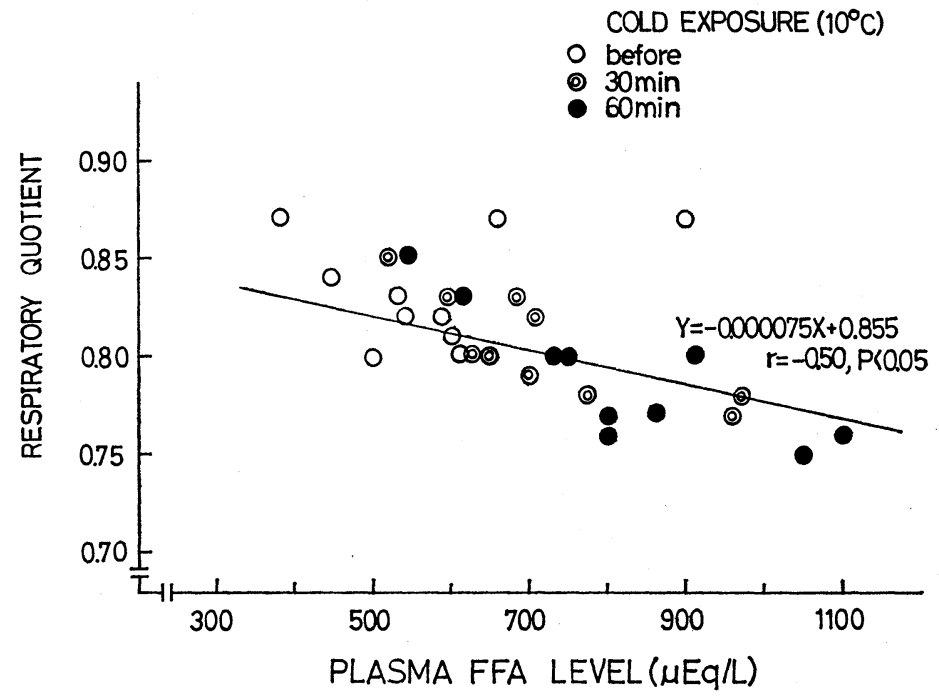

Fig. 3. Correlation between R.Q. and plasma FFA levels. Legends same as in Fig. 2.

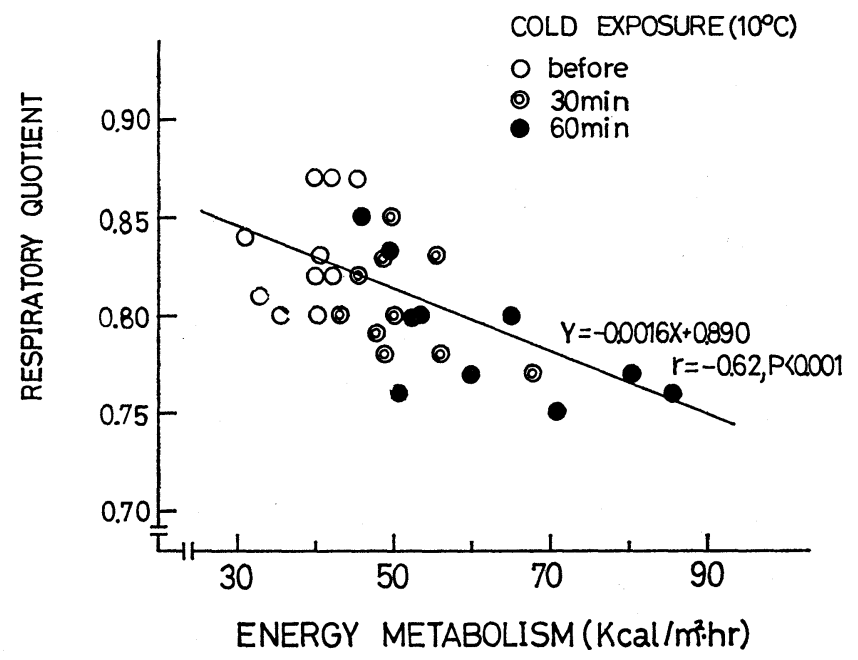

Fig. 4. Correlation between R.Q. and heat production. Legends same as in Fig. 2.

sociated with a greater utilization and mobilization of FFA.

Ketone bodies have been shown to be another substrate for heat production. Their functions are considered to be analogous to those of FFA and glucose (KREBS, 1961). Exposure to cold induced a significant increase of ketone body formation in men (Iтон, 1974). This was the case in the present study. Elevation of plasma ketone body measured as $\beta$-hydroxybutyrate was observed 60 min after 
cold exposure in the control study $(p<0.05)$ (Table 4). However, the extent of increase in ketone body levels was not so great as that in FFA. An enhanced peripheral utilization of plasma FFA and/or ketone bodies may be responsible for less increment of plasma ketone body than that of plasma FFA. On the other hand, the plasma ketone body level significantly decreased $30 \mathrm{~min}$ and $60 \mathrm{~min}$ after cold exposure (respectively, $p<0.001$ ) from the initial level in the nicotinic acid study, possibly resulting from less mobilization of FFA. It has been shown by JEANRENAUD (1961) that the ketone body formation is proportional to the concentration of FFA in the plasma.

As described in RESULTS, the blood glucose level remained at the initial levels during cold exposure. Lower R.Q. and no changes in plasma glucose level after cold exposure indicate that blood glucose does not play a great role as an energyyielding substrate in the cold at least in the present study and further that the stimulus for increased fat mobilization is mediated primarily by norepinephrine released by the sympathetic nerves rather than adrenal medulla (WILson et al., 1969).

Since it is known that nicotinic acid has a vasodilatating effect (ABRAMSON et al., 1940) besides the action of inhibiting the release of FFA, the effect of this drug on thermal response to cold should be taken into consideration. In fact, the subcutaneous flushing on the face and the extremities appeared 3 to 5 min after an administration of nicotinic acid at the room temperature of $25^{\circ} \mathrm{C}$, continuing for $5 \mathrm{~min}$ and then faded gradually. However, in the cold environment nicotinic acid showed only faint sign of vasodilatation. It could be supposed that the enhanced vasoconstricting activity due to cold stress outbalanced the transient effect of vasodilatation due to nicotinic acid. This finding is reflected in the result that there was no significant difference in the mean skin temperature, although it tends to be higher in the nicotinic acid study, and hence in the body heat loss between control and nicotinic acid studies. In addition, there was no significant difference in the variations of rectal temperatures, in the rate of fall of mean body temperature, heat content, heat debt, and heat loss between two studies. Therefore, it is unlikely that nicotinic acid itself altered the heat loss mechanism during cold exposure in the present study.

It has been previously shown that thyroid hormones are also important in regulating nonshivering thermogenesis (CHAFFEE and RoBERTS, 1971). Recently, several investigators reported a high level of plasma thyroid hormones in the winter in men (Rastogi and Sawhney, 1976; Nagata et al., 1976; Smals et al., 1977). Therefore, it is surmised that thyroid hormones are involved in the presence of nonshivering thermogenesis observed here in men living in the northern area. But this problem remains to be studied in future. 


\section{REFERENCES}

Abramson, D. I., Katzenstein, K. H., and Senior, F. A. (1940) Effect of nicotinic acid on peripheral blood flow in man. Am. J. Med. Sci., 200: 96-102.

Allen, T. H., Peng, M. R., Chen, C. P., Huang, R. F., Chang, C., and Fang, H. S. (1956) Symposium on nutrition: Prediction of total adiposity from skinfolds and the curvilinear relationship between external and internal adiposity. Metabolism, 5: 346-352.

Burton, A. C. and Edholm, O. G. (1955) Man in a Cold Environment, Edward Arnold, Ltd., London, p. 41.

Buskirk, E. R., Thompson, R. H., and Whedon, G. D. (1963) Metabolic response to cold air in men and women in relation to total body fat content. J. Appl. Physiol., 18: 603-612.

Carlson, L. D. (1954) Man in a Cold Environment: A Study in Physiology, Armed Services Technical Information Agency, Dayton, Ohio, pp. 1-2.

Chaffee, R. R. J. and Roberts, J. C. (1971) Temperature acclimation in birds and mammals. Annu. Rev. Physiol., 33: 155-202.

DAvis, T. R. A. (1961) Chamber cold acclimatization in man. J. Appl. Physiol., 16: 1011-1015.

DAvis, T. R. A. and Johnston, D. R. (1961) Seasonal acclimatization to cold in man. J. Appl. Physiol., 16: 231-234.

Doi, K., KURoshima, A., and Iтон, S. (1969) Effects of nicotinic acid on plasma free fatty acid level and basal energy metabolism in man. J. Physiol. Soc. Jpn., 31: 705-706.

Gibbard, S. and Watkins, P. J. (1968) A micro-method for the enzymatic determination of $d-\beta$-hydroxybutyrate and acetoacetate. Clin. Chim. Acta, 19: 511-521.

Girling, G. (1964) Metabolic response of nude human subjects to acute exposure at $10^{\circ} \mathrm{C}$. Can. J. Physiol. Pharmacol., 42: 319-327.

Glickman, N., Mitchel, H. H., Keelton, R. W., and Lambert, E. H. (1967) Shivering and heat production in men exposed to intense cold. J. Appl. Physiol., 22: 1-8.

HART, J. S., HÉroux, O., and Depocas, F. (1956) Cold acclimation and the electromyogram of unanesthetized rats. J. Appl. Physiol., 9: 404-408.

Havel, R. J., Carlson, L. A., Ekelund, L. G., and Holmgren, A. (1964) Studies on the relation between mobilization of free fatty acids and energy metabolism in man: effects of norepinephrine and nicotinic acid. Metabolism, 13: 1402-1411.

Hurley, D. A., Topliff, E. D. L., and Girling, F. (1964) Acute exposure of human subjects to an ambient temperature of $10^{\circ} \mathrm{C}$. Can. J. Physiol. Pharmacol., 42: 233-243.

IRviNG, L. (1960) Human adaptation to cold. Nature, 185: 572-574.

ITAYA, K. and UI, M. (1965) Calorimetric determination of free fatty acids in biological fluids. J. Lipid Res., 6: 16-20.

Iтон, S. (1974) Physiology of Cold-Adapted Man, Hokkaido University Medical Library Series Vol. 7, Hokkaido University School of Medicine, Sapporo, Japan.

Itoh, S., Kuroshima, A., Doi, K., Moriya, K., Shirato H., and Yosh ${ }_{\mathrm{I}}^{\mathrm{MuRA}}$, K. (1969) Lipid metabolism in relation to cold adaptability in man. Fed. Proc., 28: 960-964.

Jeanrenaud, B. (1961) Dynamic aspects of adipose tissue metabolism: A review. Metab. Clin. Exp., 10: 535-581.

Joy, R. J. T. (1963) Responses of cold-acclimated men to infused norepinephrine. J. Appl. Physiol., 18: 1209-1212.

Kang, B. S., Han, D. S., Paik, K. S., Park, Y. S. Kim, J. K., Kim, C. S., Rennie, D. W., and HoNG, S. K. (1970) Calorigenic action of norepinephrine in the Korean women divers. J. Appl. Physiol., $29: 6-9$.

Krebs, H. A. (1961) The physiological role of the ketone bodies. Biochem. J., 80: 225-233.

Kuroshima, A., Nakata, H., OHno, T., Hayami, O., and Kawarabayashi, T. (1973) Seasonal variations in lipid and protein metabolism of men and rabbits living in a cold area. Hok-

Vol. 29, No. 4, 1979 
kaido J. Med. Sci., 48: 341-348.

Masoro, E. J. (1966) Effect of cold on metabolic use of lipids. Physiol. Rev., 46: 67-101.

MorRIson, P. (1965) Body temperature in some Australian mammals. V. Aboriginals. $J$. Appl. Physiol., 20: 1278-1282.

Nagata, H., Izumiya, T., Kamata, K., Kono, S., Yukimura, Y., Tawata, M., Aizawa, T., and YAMADA, T. (1976) An increase of plasma triiodothyronine concentration in man in a cold environment. J. Clin. Endocrinol. Metab., 43: 1153-1156.

Ohno, T. and Kuroshima, A. (1973) Ages and seasonal variations of basal metabolism. Jpn. J. Biometeorol., No. 9: 12.

Rastogi, G. K. and SAwhNeY, R. C. (1976) Thyroid function in changing weather in a subtropical region. Metabolism, 25: 903-908.

RoE, J. H. (1955) The determination of sugar in blood and spinal fluid with anthrone reagent. J. Biol. Chem., 212: 335-343.

Sellers, E. A., Scott, J. W., and Thomas, H. (1954) Electrical activity of skeletal muscle of normal and acclimatized rats on exposure to cold. Am. J. Physiol., 177: 372-376.

Smals, A. G. H., Ross, H. A., and Kloppenborg, P. W. C. (1977) Seasonal variation in serum $\mathrm{T}_{3}$ and $\mathrm{T}_{4}$ levels in man. J. Clin. Endocrinol. Metab., 44: 998-1001.

SwIFT, R. W. (1932) The effects of low environment temperature upon metabolism. I. Technic and respiratory quotient. J. Nutr., 5: 213-225.

Wilson, O., Laurell, S., and Tibbling, G. (1969) Effect of acute cold exposure on blood lipids in man. Fed. Proc., 28: 1209-1215. 